\title{
The right treatment for the right patient with COPD: lessons from the IMPACT trial
}

\author{
Daiana Stolz ${ }^{1}$ and Marc Miravitlles (10) ${ }^{2}$
}

Affiliations: ${ }^{1}$ Clinic of Respiratory Medicine and Pulmonary Cell Research, University Hospital, Basel, Switzerland. ${ }^{2}$ Pneumology Dept, Hospital Universitari Vall d'Hebron/Vall d'Hebron Research Institute, CIBER de Enfermedades Respiratorias (CIBERES), Barcelona, Spain.

Correspondence: Marc Miravitlles, Pneumology Dept, Hospital Universitari Vall d'Hebron, Pg. Vall d'Hebron 119-129, 08035 Barcelona, Spain. E-mail: marcmdasepar.es

@ERSpublications

Different patient characteristics have to be considered for prescription of triple therapy in COPD https://bit.ly/2xWq7lW

Cite this article as: Stolz D, Miravitlles M. The right treatment for the right patient with COPD: lessons from the IMPACT trial. Eur Respir J 2020; 55: 2000881 [https://doi.org/10.1183/13993003.00881-2020].

Long-acting bronchodilators are the basis of treatment for COPD [1]; however, there are some patients who suffer from frequent or severe exacerbations, despite maximal bronchodilation [2]. These patients are at increased risk of death and represent a great challenge in clinical practice [3]. Inhaled corticosteroids (ICS) are the basis of the treatment of asthma and are also effective, albeit to a lesser extent, in some patients with COPD [4]. Generally speaking, ICS are indicated in patients with COPD and exacerbations, despite bronchodilator treatment [1]. However, not all COPD patients respond to ICS and the long-term use of ICS in COPD may be associated with several side-effects $[5,6]$. Therefore, the use of ICS for the prevention of exacerbations in COPD should not be a treatment "by default" and must be guided by criteria based on evidence [7]. In this respect, the InforMing the PAthway of COPD Treatment (IMPACT) study has provided very relevant information about the proper use of ICS, either in combination with a long-acting $\beta_{2}$-agonist (LABA) or in triple therapy with a LABA and a long-acting antimuscarinic agent (LAMA) [8]. The IMPACT trial included 10355 patients with COPD, randomised to receive a once-daily combination of fluticasone furoate (FF), umeclidinium (UMEC) and vilanterol (VI) (triple therapy), FF/VI or UMEC/VI, all administered in a single Ellipta inhaler during the 52-week study. The primary outcome was the annual rate of moderate or severe COPD exacerbations during treatment. The rate of exacerbations with triple therapy was a significant $15 \%$ lower compared with the FF/VI group and 25\% lower compared with the UMEC/VI group, and there was a significantly higher incidence of pneumonia in the ICS groups than in the UMEC/VI group [8].

Based on these results, the conclusion appears to be that all COPD patients with frequent or severe exacerbations should be on triple therapy; unfortunately, however, things are not so simple [9-11]. First, we need to be aware that these results were generated from patients with either a forced expiratory volume in $1 \mathrm{~s}\left(\mathrm{FEV}_{1}\right)$ that was less than $50 \%$ of predicted and a history of at least one moderate or severe exacerbation in the previous year, or an $\mathrm{FEV}_{1}$ of 50 to $80 \%$ and at least two moderate exacerbations or one severe exacerbation in the previous year, while on their usual inhaled therapy [8]. These patients account for no more than one third of patients with COPD attended by pulmonary specialists $[2,12]$, and are even fewer in primary care $[13,14]$. Second, the risk/benefit balance of ICS may depend on a series of factors, such as active smoking, blood eosinophil count (BEC) and coexistent asthma, among others. In this respect, although patients with a current diagnosis of asthma were excluded from the IMPACT study, 
the past history of asthma was not an exclusion criterion [8], and it is unknown how this may have influenced the results in favour of the ICS-containing treatment groups. In fact, the latest update of the Global Initiative for Chronic Obstructive Lung Disease (GOLD) document includes a history of asthma as a criterion strongly supporting the use of ICS in COPD [1].

A huge study such as IMPACT can better investigate which factors modulate the response to ICS in terms of efficacy in the prevention of exacerbations. The steering committee and the sponsor of the study have to be acknowledged for their commitment to delivering results that will clarify the role of different inhaled medications for the most challenging patients with COPD. Indeed, a recent secondary analysis demonstrated that the magnitude of benefit of regimens containing ICS in reducing rates of exacerbations increased in proportion with BEC, compared with LABA/LAMA, and former smokers were more corticosteroid responsive at any eosinophil count than current smokers [15]. In addition, since the beneficial effect of ICS on exacerbations was greater at higher BECs for exacerbations requiring oral corticosteroids or antibiotics and oral corticosteroids, there was no clear relationship with BECs for patients requiring only antibiotics, and triple therapy offered no significant added benefit over LABA/ LAMA at any BEC [15].

In the current issue of the European Respiratory Journal, Halpin et al. [16] extend these observations by presenting another secondary analysis of the IMPACT trial aimed at investigating how a previous history of exacerbations modulates the effect of the different treatments in the prevention of exacerbations. Not surprisingly, the first result of this analysis was that the best predictor of future exacerbation risk was the history of previous exacerbations, and the best predictor of a severe exacerbation was having had a severe exacerbation the previous year [16]. Nevertheless, only around $50 \%$ of these symptomatic COPD patients at high risk of exacerbation experienced at least one exacerbation during the year of the study. This observation has been previously described in other trials and highlights that even patients who presented severe or recurrent exacerbations in the previous year might remain clinically stable for longer periods of time irrespective of medical therapy. Thus, evaluation of the efficacy of treatments for prevention of exacerbations in individual patients based on exacerbation recurrence rates might be misleading.

Regarding the comparison between treatment arms, patients who had had only one moderate exacerbation the previous year (and $\mathrm{FEV}_{1}<50 \%$ ) represented approximately $30 \%$ of the study population and can be considered infrequent exacerbators with severe COPD. In this subgroup, the annual rate of exacerbations with triple therapy was significantly reduced compared with FF/VI (rate ratio (RR) 0.80) and with UMEC/ VI (RR 0.82), but the risk reduction point of triple therapy versus UMEC/VI was not significant (hazard ratio (HR) 0.92 , 95\% CI 0.76-1.02) [16]. A possible explanation is that differences in exacerbation rates were due to a slightly higher number of patients in the UMEC/VI arm who experienced three or more on-treatment exacerbations. On the other hand, there was no significant difference in the annual rate of severe exacerbations between groups. Interestingly, exacerbation rates between triple therapy and UMEC/ VI only started to diverge at BECs $>200$ cells per $\mu \mathrm{L}$. In general, the results of the comparison between FF/ VI and UMEC/VI in this population of infrequent exacerbators favoured UMEC/VI and were in agreement with the results of the FLAME study $[17,18]$.

In the group of patients with frequent moderate exacerbations in the previous year, the annual rate and risk of exacerbations, as well as the annual rate of severe exacerbations on treatment were significantly lower with triple therapy compared with UMEC/VI. Regarding the BEC, the exacerbation rates between the two treatment arms were similar only at BECs $<100$ cells per $\mu \mathrm{L}$ [16]. In contrast to the FLAME study $[17,18]$, in this population of frequent exacerbators, FF/VI provided better results than UMEC/VI in the prevention of exacerbations, in particular at BECs $>200$ cells per $\mu \mathrm{L}$.

Finally, in patients with at least one severe exacerbation in the previous year, the results were similar to those observed in the previous group of patients with frequent moderate exacerbations. Exacerbation rates were similar only at BECs $<100$ cells per $\mu \mathrm{L}$. Above this level, ICS containing treatments had lower rates of exacerbations than the UMEC/VI group. The results of other secondary outcomes such as lung function and quality of life followed a similar pattern to that observed with exacerbations [16].

What are the implications of these results for the practicing clinician?

1) The IMPACT study confirms that not only BEC, but also smoking status, previous history of exacerbations and type of exacerbations modulate the response to ICS in COPD [19, 20] (figure 1).

2) LABA/ICS only has greater effects than LABA/LAMA in patients with higher BEC and frequent and/ or severe exacerbations. However, in these patients, triple therapy is superior to LABA/ICS [21-24] and, therefore, there is not much room for LABA/ICS in the treatment of COPD [25].

3) It makes no sense to add an ICS to dual bronchodilation in patients with a BEC $<100$ cells per $\mu \mathrm{L}$ and without a history of asthma, even if they are frequent exacerbators $[7,26]$. 


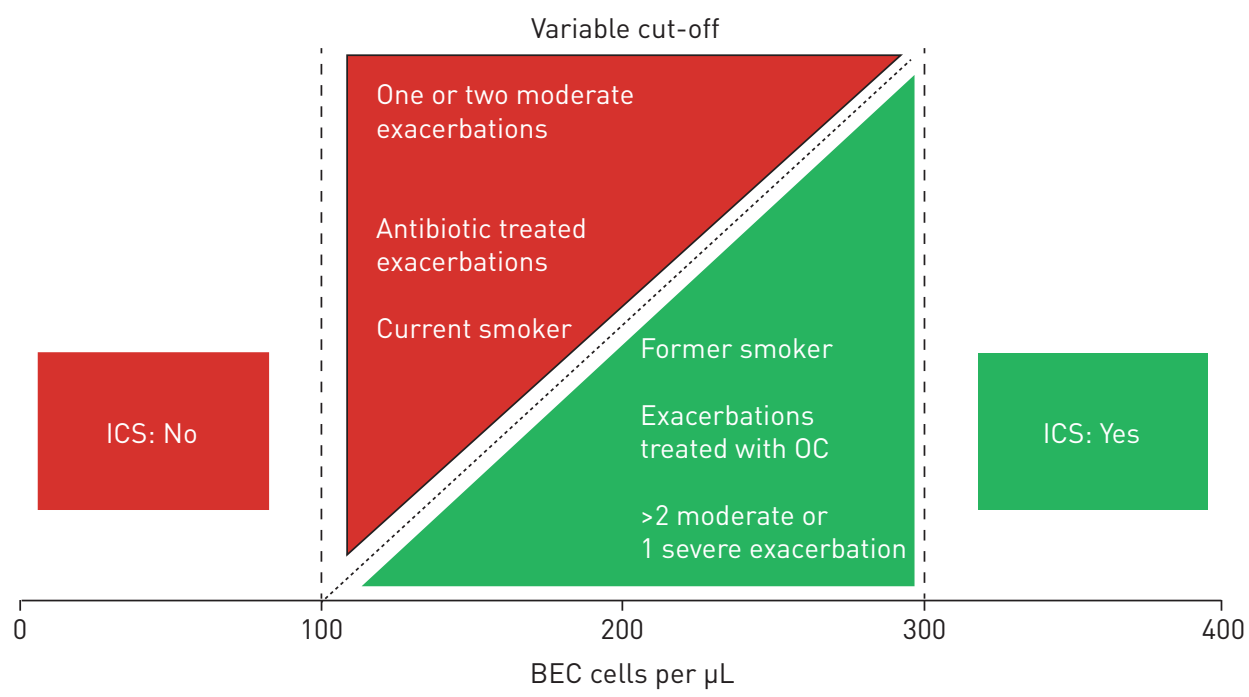

FIGURE 1 Indication of inhaled corticosteroids (ICS) in COPD according to blood eosinophil counts (BEC) and other factors. ICS are indicated for prevention of exacerbations in patients with BEC $>300$ cells per $\mu \mathrm{L}$ and not indicated with BEC $<100$ cells per $\mu \mathrm{L}$. The cut-off of BEC for the use of ICS in the range between 100 and 300 cells per $\mu \mathrm{L}$ may vary according to the presence of other factors that modulate the response. Factors in the red triangle reduce the response to ICS and increase the BEC cut-off, and those in the green triangle increase the response to ICS and decrease the cut-off. As an example, a former smoker with a previous hospitalisation may require ICS even at BECs of 150 cells per $\mu \mathrm{L}$ or less, whereas an active smoker with only one moderate exacerbation should not be prescribed ICS at BECs below 200 or even 250 cells per $\mu \mathrm{L}$. OC: oral corticosteroids.

4) All patients with frequent or severe exacerbations and a BEC $>300$ cells per $\mu \mathrm{L}$ should receive triple therapy $[7,21,24,26]$.

5) The GOLD recommendation to consider ICS in patients with a BEC between 100 and 300 cells per $\mu \mathrm{L}$ and one moderate exacerbation has to be revisited [1], because in this subgroup there was no clear advantage of triple therapy over UMEC/VI [16]. There was only a reduction in the annual rate of exacerbations, apparent only in patients with a BEC $>200$ cells per $\mu \mathrm{L}$, but not in the risk rate, due to the small number of patients with more frequent on-treatment episodes. Therefore, in the great majority of these patients, there was no significant effect of adding an ICS to LABA/LAMA [27]. Furthermore, more than $50 \%$ of patients in the single moderate subgroup did not have any on-treatment exacerbation, regardless of the treatment arm. Finally, these results were obtained in patients with one moderate exacerbation and a $\mathrm{FEV}_{1}<50 \%$, but most patients with a single moderate exacerbation per year have milder disease, and are, therefore, more likely not to repeat the episode and not to require an ICS $[13,14]$.

The IMPACT study has confirmed the current thinking that exacerbators with a BEC $<100$ cells per $\mu \mathrm{L}$ should not receive ICS, and those with a BEC $>300$ cells per $\mu \mathrm{L}$ should always be treated with ICS $[1,7]$; more importantly, this study has offered some relevant clues to identify which exacerbators with BECs between 100 and 300 cells per $\mu \mathrm{L}$ should also be on ICS (figure 1). This is crucial, because the majority of patients with COPD present BECs within this interval [28], and the variability in BEC also has to be considered [29].

Conflict of interest: D. Stolz reports grants from AstraZeneca AG, Curetis AG and Boston Scientific, personal fees for lectures from AstraZeneca AG, Novartis AG, GSK AG, Roche AG, Zambon, Pfizer, Schwabe Pharma AG and Vifor AG, outside the submitted work. M. Miravitlles reports personal fees for lectures from AstraZeneca, Boehringer Ingelheim, Chiesi, Cipla, Menarini, Rovi, Bial, Zambon, Sandoz, CSL Behring, Grifols and Novartis, personal fees for consultancy from AstraZeneca, Boehringer Ingelheim, Chiesi, GlaxoSmithKline, Bial, Gebro Pharma, CSL Behring, Laboratorios Esteve, Ferrer, Mereo Biopharma, Verona Pharma, Kamada, TEVA, Sanofi, pH Pharma, Novartis and Grifols, grants from GlaxoSmithKline and Grifols, outside the submitted work.

\section{References}

1 Singh D, Agusti A, Anzueto A, et al. Global Strategy for the Diagnosis, Management, and Prevention of Chronic Obstructive Lung Disease: the GOLD science committee report 2019. Eur Respir J 2019; 53: 1900164.

2 Hurst JR, Vestbo J, Anzueto A, et al. Susceptibility to exacerbation in chronic obstructive pulmonary disease. N Engl J Med 2010; 363: 1128-1138. 
3 Alcázar Navarrete B, Ancochea Bermúdez J, García-Río F, et al. Patients with chronic obstructive pulmonary disease exacerbations: recommendations for diagnosis, treatment and care. Arch Bronconeumol 2019; 55: 478-487.

4 D'Urzo A, Donohue JF, Kardos P, et al. A re-evaluation of the role of inhaled corticosteroids in the management of patients with chronic obstructive pulmonary disease. Expert Opin Pharmacother 2015; 16: 1845-1860.

5 Price DB, Voorham J, Brusselle G, et al. Inhaled corticosteroids in COPD and onset of type 2 diabetes and osteoporosis: matched cohort study. NPJ Prim Care Respir Med 2019; 29: 38.

6 Nieto A, Mazon A, Pamies R, et al. Adverse effects of inhaled corticosteroids in funded and nonfunded studies. Arch Intern Med 2007; 167: 2047-2053.

7 Agusti A, Fabbri LM, Singh D, et al. Inhaled corticosteroids in COPD: friend or foe? Eur Respir J 2018; 52: 1801219

8 Lipson DA, Barnhart F, Brealey $\mathrm{N}$, et al. Once-daily single-inhaler triple versus dual therapy in patients with COPD. $N$ Engl J Med 2018; 378: 1671-1680.

9 López-Campos JL, Carrasco-Hernández L, Román Rodríguez L, et al. The clinical implications of triple therapy in fixed-dose combination in COPD: from the trial to the patient. Arch Bronconeumol 2020; 56: 242-248.

10 Calverley PMA, Magnussen H, Miravitlles M, et al. Triple therapy in COPD: what we know and what we don't. COPD 2017; 14: 648-662.

11 Vanfleteren LEGW, Ullman A, Nordenson A, et al. Triple therapy (ICS/LABA/LAMA) in COPD: thinking out of the box. ERJ Open Res 2019; 5: 00185-02018.

12 Izquierdo JL, Miravitlles M, Esquinas C, et al. Characteristics of COPD patients managed in respiratory medicine departments in Spain, according to GOLD groups and GesEPOC clinical phenotypes. Arch Bronconeumol 2018; 54: 559-567.

13 Vetrano DL, Zucchelli A, Bianchini E, et al. Triple inhaled therapy in COPD patients: determinants of prescription in primary care. RespirMed 2019; 154: 12-17.

14 Izquierdo JL, Morena D, González Y, et al. Clinical management of COPD in a real-world setting. A big data analysis. Arch Bronconeumol 2020; in press [https://doi.org/10.1016/j.arbres.2019.12.025].

15 Pascoe S, Barnes N, Brusselle G, et al. Blood eosinophils and treatment response with triple and dual combination therapy in chronic obstructive pulmonary disease: analysis of the IMPACT trial. Lancet Respir Med 2019; 7: 745-756.

16 Halpin DMG, Dransfield MT, Han MLK, et al. The effect of exacerbation history on outcomes in the IMPACT trial. Eur Respir J 2020; 55: 1901921.

17 Wedzicha JA, Banerji D, Chapman KR, et al. Indacaterol-glycopyrronium versus salmeterol-fluticasone for COPD. N Engl J Med 2016; 374: 2222-2234.

18 Roche N, Chapman KR, Vogelmeier CF, et al. Blood eosinophils and response to maintenance chronic obstructive pulmonary disease treatment. data from the FLAME trial. Am J Respir Crit Care Med 2017; 195: 1189-1197.

19 Brusselle G, Pavord ID, Landis S, et al. Blood eosinophil levels as a biomarker in COPD. Respir Med 2018; 138: 21-31.

20 Oshagbemi OA, Franssen FME, van Kraaij S, et al. Blood eosinophil counts, withdrawal of inhaled corticosteroids and risk of COPD exacerbations and mortality in the Clinical Practice Research Datalink (CPRD). COPD 2019; 16: $152-159$

21 Voorham J, Corradi M, Papi A, et al. Comparative effectiveness of triple therapy versus dual bronchodilation in COPD. ERJ Open Res 2019; 5: 00106-2019.

22 Lai CC, Chen $\mathrm{CH}$, Lin $\mathrm{CYH}$, et al. The effects of single inhaler triple therapy vs single inhaler dual therapy or separate triple therapy for the management of chronic obstructive pulmonary disease: a systematic review and meta-analysis of randomized controlled trials. Int I Chron Obstruct Pulmon Dis 2019; 14: 1539-1548.

23 Buhl R, Criée CP, Kardos P, et al. Dual bronchodilation vs triple therapy in the "real-life" COPD DACCORD study. Int J Chron Obstruct Pulmon Dis 2018; 13: 2557-2568.

24 Leung JM, Sin DD. Inhaled corticosteroids in COPD: the final verdict is. Eur Respir J 2018; 52: 1801940.

25 Calzetta L, Cazzola M, Matera MG, et al. Adding a LAMA to ICS/LABA therapy: a meta-analysis of triple combination therapy in COPD. Chest 2019; 155: 758-770.

26 Cazzola M, Rogliani P, Calzetta L, et al. Triple therapy versus single and dual long-acting bronchodilator therapy in COPD: a systematic review and meta-analysis. Eur Respir J 2018; 52: 1801586.

27 Suissa S, Ariel A. Triple therapy trials in COPD: a precision medicine opportunity. Eur Respir J 2018; 52 : 1801848.

28 Miravitlles M, Monteagudo M, Solntseva I, et al. Blood eosinophil counts and their variability and risk of exacerbations in COPD: a population-based study. Arch Bronconeumol 2020; in press [https://oi.org/10.1016/j. arbres.2019.12.015].

29 Schumann DM, Tamm M, Kostikas K, et al. Stability of the blood eosinophilic phenotype in stable and exacerbated COPD. Chest 2019; 156: 456-465. 